\title{
Sensory Qualities, Sensible Qualities, Sensational Qualities
}

\begin{abstract}
Alex Byrne
In theorizing about perception, philosophers have often multiplied qualities. To perceptible qualities of external objects, like colors and shapes ('sensible' qualities), have been added qualities of experiences ('sensory' qualities) or of sense-data ('sensational' qualities). Start with sensory qualities. The phrase 'sensory quality' is not much in use these days, having lost out to 'phenomenal character,' 'phenomenal property,' 'qualitative character,' or 'quale.' But whatever sensory qualities are called, pinning them down is no easy matter.
\end{abstract}

\section{Sensory qualities}

Austen Clark's Sensory Qualities can serve as an initial illustration, especially because this important book is in general an exemplary specimen of clarity and rigor. If the elusiveness of sensory qualities is apparent here, then a large part of the blame can be apportioned to the subject matter itself. Clark opens the explanation of his topic as follows:

A whiff of lilacs presents a particular sweet odour. The warmth of the rising sun yields certain tactile sensations. Bees' honey has a specific taste. The qualities that characterize the smell of the lilacs, sensation of the sun, or taste of the honey are all what I will call sensory qualities.

Broadly speaking, such qualities characterize what it is like to sense or perceive things. One perceives the blooms, sun and honey in a particular way; sensory qualities characterize the way such things appear. (Clark 1993, p. 1). 
It is not immediately clear from these two paragraphs what sensory qualities are qualities of. Consider the 'sweet odour' of lilacs. We may take the odour of lilacs to be the same as 'the smell of the lilacs,' in which case one quality that presumably 'characterize[s] the smell of the lilacs' is sweetness. And what is the smell of the lilacs? One candidatereading 'the smell of the lilacs' like 'the color/size of the lilacs' — is a certain odiferous property of the lilacs. On this reading, sweetness 'characterizes' the smell of the lilacs in the sense that it is identical to the smell-it is identical to an odiferious property of the lilacs. Another candidate for the smell of the lilacs — leaning heavily on the fact that smells 'drift,' 'linger,' and are 'given off' by objects like lilacs—is a certain volume of gas, an “effluvium" (Gibson 1966, p. 144), or "vaporous emanation" (Lycan 1996, p. 146). On this rival account, sweetness 'characterizes' the smell of the lilacs in the sense that it is a property of the smell—the effluvium emitted by the lilacs. In any case, there do not seem to be any mental candidates for the smell of the lilacs: if the smell is anywhere, it is in the lilac bed, not the mind.

So, if we focus on Clark's first example, sensory qualities are not properties of anything mental. But his second example - the 'sensation of the sun'—and the tell-tale 'what it is like' locution suggest exactly the opposite, that sensory qualities attach to mental items (experiences, probably). However, Clark goes on to say that sensory qualities 'characterize the way such things [the blooms, sun and honey] appear.' Since the blooms appear red, the sun appears hot, and the honey appears sweet (suppose), sensory qualities 'characterize' redness, hotness, and sweetness, for example. Either this means that sensory 
qualities are (higher-order) properties of redness, hotness, etc., or else it means (a more likely interpretation) that the redness, hotness, etc., are examples of sensory qualities. Either way, sensory qualities are not—or are not obviously_properties of experiences. This is somewhat unfair to Clark - it is perfectly clear from other passages that sensory qualities are stipulated to be properties of experiences or, as he prefers, 'sensations':

\begin{abstract}
Although 'sensation' proper is a term confined to bodily sensation, often one extends its use to describe appearances in all perceptual modalities. Whenever any creature perceives something, there is some internal state of the creature in virtue of which it perceives that thing. One can label that state the creature's 'sensation of' or 'sense impression of' or 'experience of' the perceived thing. So, for example, the internal state in virtue of which I now see the red rug and without which I would not see the red rug is (by stipulation) my visual sensation 'of' the rug. Sensory qualities are qualities of sensation, construed in this broad way. (Clark 1993, pp. 3-4).
\end{abstract}

A number of questions can be raised about this explanation. First, there is a contrast between states and events_-states are properties or conditions, not occurrences or events, although frequently philosophers of mind use 'state' in a semi-technical umbrella sense to include events. Clark might be assuming that sensations are events, and using 'state' in the broad sense. If so, then sensory qualities are properties of particulars; alternatively, if Clark is using 'state' in the narrow sense, they are properties of properties. If it is unclear which 
option to choose, that casts some doubt on the idea that 'sensory quality' is a label for something we all pre-theoretically recognize.

Second, is it even true that "when a creature perceives something, there is some internal state of the creature in virtue of which it perceives that thing'? Setting aside the state/event distinction, much hangs on the interpretation of 'in virtue of,' which Clark leaves unexplained. One suggestion would be that 'seeing the red rug' can be decomposed into an internal state (the 'sensation'), the red rug, and an appropriate causal relation connecting the rug to the internal state. But that would require an argument: the decomposition thesis is considerably stronger than the relatively uncontroversial claim that a causal connection is necessary for seeing.

Third, are we aware of sensations and their sensory qualities? That might sound like a silly question - one is frequently aware of one's bodily sensations ('sensations proper') and some of their properties. I am aware of a twinge, its location (my left elbow), and its achiness. That sort of awareness seems (quasi-)perceptual—rather like the awareness I have of a flash of light, its location (the far side of the room), and its brightness. However, on this conception of (bodily) sensations, they are not experiences - rather, they are objects of experiences. The twinge is — or at any rate appears to be — some sort of disturbance in my elbow, not in my mind or head, unlike the presumed 'experience' of the twinge. Clark, however, has a very different conception of bodily sensations, on which the experience of the twinge, not the twinge, counts as a bodily sensation- - hence his extension of the use of 'sensation' to cover paradigmatic perceptual experiences. Without distinguishing between 
the two conceptions of sensations, it might appear evident that we are aware of sensations (as Clark conceives of them) and their sensory qualities - in fact, it is far from evident.

For these reasons, it should not be taken for granted that Clark has succeeded in circumscribing his purported object of study. For another attempt, consider how Levine

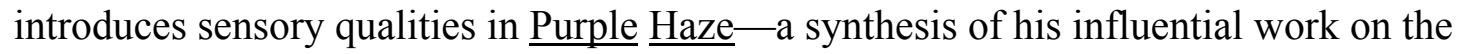
'explanatory gap':

Let's take my current visual experience as I gaze upon my red diskette case, lying by my side on the computer table. I am having an experience with a complex qualitative character, one component of which is the color I perceive. Let's dub this aspect of my experience its "reddish" character ... Qualitative character concerns the "what" it's like for me: reddish or greenish, painful or pleasurable, and the like. From within the subjective point of view I am presented with these qualitative features of experience, or "qualia," [a.k.a. sensory qualities] as they are called in the literature. Reddishness, for instance, is a feature of my experience when I look at my red diskette case. It is notoriously difficult to explain this feature by reference to either the physical or formal features of my brain states. (Levine 2001, pp. 6-7; note omitted)

Plainly Levine intends sensory qualities ('qualitative character,' 'qualitative features,' 'qualia') to be properties of experiences, although he says little about what experiences are supposed to be. Suppose one is looking at Levine's red diskette case, balanced precariously 
on the computer table. One might be aware of a state of the diskette case (its redness), and an event involving the diskette case (its falling off the table). Is it so obvious that one can also be aware of, or be 'presented with,' a 'qualitative feature' of a mental event or stateone's experience of the diskette case? Uncontroversially, one is in a position to know that one sees the diskette case, and that it looks red to one. What is not immediately clear is whether this piece of self-knowledge requires any kind of awareness of a mental event or state. Indeed, the very existence of an appropriate event is a matter of some doubt. 'One's seeing the diskette case,' for example, is not a good candidate for such an event - the nominal 'one's seeing the diskette case' behaves more like the name of a fact than of an event (see Bennett 1988, ch. 1). (On the difficulty of squeezing some philosophical juice out of the word 'experience,' see Hinton [1973, pt. I].)

Of course, one can easily play along with Levine's terminology, at least to some extent, by saying 'My experience is reddish' iff it looks to one that something is red. But Levine does not intend 'reddish experiences' to be a stylistic variant of 'looks red' and similar expressions (and this article will follow Levine's terminological intentions). Levine evidently assumes that we have some independent handle on reddish experiences, and that the relation between reddish experiences and how things look with respect to color is an open question. The role played by the red appearance of the diskette case is merely to fix the reference of 'reddish' - the relation between reddish experiences and the visual 
representation of the color red might well be entirely contingent. And, in fact, that is exactly what Levine thinks (Levine 2001, ch. 4). ${ }^{1}$

\section{Sensory qualities and sensible qualities}

Sensory qualities — if there are any — are properties of experiences. They are not properties of external objects like diskette cases and the like. Going by the quotation from Levine, sensory qualities are not even ostensible properties of diskette cases_-properties of experiences that appear mistakenly to be properties of diskette cases. Introspection, attention to one's experience, acquaintance, or something similar, seems to reveal them as properties of experiences, and that is indeed what they are.

Levine's sensory quality of reddishness, then, is not redness, the color. Even if tomatoes are not in fact red, at least they appear red. And one's experiences do not appear red at all. Levine himself is quite explicit that redness and reddishness are distinct (see Levine 2001, p. 179, n. 5).

Redness can be called a sensible quality — a quality that one perceives, like roundness, motion, and sweetness. (To say that one 'perceives redness' when looking at a tomato is not to presuppose that the tomato is red.) Clark's $\underline{A} \underline{\text { Theory }} \underline{\text { of }} \underline{\text { Sentience }}$ distinguishes between sensible and sensory qualities, using the terminology of

\footnotetext{
${ }^{1}$ One notable argument for contingency is presented in Block (1990). It should be noted that Clark's views on sensory qualities are generally quite different from Levine's (see Clark 2000, pp. 22, 35-38).
} 
'phenomenal' and 'qualitative' properties (Clark 2000, p. 2). Although sensible and sensory qualities should not be identified, presumably they are closely related. But before canvassing one popular account of their relation (in section 5), it needs to be pointed out that separating the two is, for the most part, a comparatively recent innovation. Hume, for example, reports that the "fundamental principle" of the "modern philosophy" "is the opinion concerning colours, sounds, tastes, smells, heat and cold; which it asserts to be nothing but impressions in the mind" (Hume 1739-1740/1978, I, iv). By saying that colors are "impressions in the mind," and so "internal existences," Hume is (arguably) saying that items "in the mind" are colored. And if we suppose that the items are experiences (for an alternative, see the following section), then Hume is apparently identifying sensible and sensory qualities.

F.A. Hayek's The Sensory Order provides a mid-twentieth century example of this identification (as well as a notable example of the use of 'sensory quality'). Hayek begins by explaining that

[f]or the purposes of this discussion we shall employ the term sensory 'qualities' to refer to all the different attributes or dimensions with regard to which we differentiate in our responses to different stimuli. We shall thus use this term in a wide sense in which it includes not only quality in the sense in which it is contrasted with intensity, extensity, clearness, etc., but in a sense in which it includes all these other attributes of a sensation. We shall speak of sensory qualities and the sensory order to distinguish these from the affective qualities and the other mental 'values' 
which make up the more comprehensive order of 'mental qualities'. (Hayek 1952, p. 2)

Sensory qualities, then, are mental qualities, specifically 'attributes of a sensation.' And sensations, or "sense experiences" (Hayek 1952, p. 3), are "events taking place in some organism" (Hayek 1952, p. 16).

Immediately after giving this explanation Hayek says:

A precise statement of the problem raised by the existence of sensory qualities must start from the fact that the progress of the physical sciences has all but eliminated these qualities from our scientific picture of the external world. (Hayek 1952, p. 2)

In a footnote he quotes from Planck's $\underline{A} \underline{\text { Survey }} \underline{\text { of Physics: }}$

The sense perceptions have been definitely eliminated from physical acoustics, optics, and heat. The physical definitions of sound, color, and temperature are today in no way associated with the immediate perception of the respective senses, but sound and colour are defined respectively by the frequency and wavelength of oscillations, and temperature is measured theoretically on the absolute temperature scale corresponding to the second law of thermodynamics. (Planck 1926, p. 5) 
So the sensory qualities — as Hayek goes on to say—include "colours, sounds, odours, feeling of touch, etc." (Hayek 1952, p. 3). Science has only turned up correlates of these qualities in our external environment— 'the frequency and wavelength of oscillations'—not the qualities themselves.

Suppose that Hume and Hayek are right, and that nothing in the external world is colored or noisy or tasty. What remains quite unclear is why they think items in the 'internal' world—sensations, for instance—-have these qualities. Why not say instead that absolutely nothing has these qualities?

Whatever the answer to this question might be, the introspective psychologists tended to take it as simply obvious that 'sensations' had colors, sounds, and so forth:

Sensations have always been distinguished by their qualities. Every sensation can be said to have an attribute of quality, which designates it as red or yellow or bitter or cold or C\#. (Boring 1933, p. 19)

Returning to Clark's Sensory Qualities, soon it becomes apparent that he is working squarely within this framework. Examples of "a particular sensory quality" include "a red colour or a camphoraceous odour" (Clark 1993, p. 128). So the familiar color solid, with the colors arranged along dimensions of hue, brightness, and saturation, is taken to be a space of sensory qualities - and the main task of Clark's book is to supply a broadly physicalistic theory of such spaces. 
One way of justifying this surely rather odd talk is to take 'red,' 'camphoraceous,' and so forth, to be ambiguous. In one sense, 'red' refers to a property of tomatoes and strawberries; in another sense, 'red' refers to a property of mental items - experiences, sensations, or whatever. Locke is often supposed to hold such a view (for discussion, see Stuart [2003]). However, taken as a descriptive semantic claim about English, the ambiguity thesis is not very appealing. Phrases like 'red experience' and 'red sensation' cannot be adduced in its support, since these are examples of philosophical jargon, not ordinary English. 'An experience of red' is fairly natural, but here there is no reason to suspect that 'red' has a second semantic value ('the Taj Mahal' in 'an experience of the Taj Mahal' refers to the mausoleum, not to anything mental). ${ }^{2}$

\section{Sensational qualities}

In his famous 1903 paper 'The refutation of idealism,' G.E. Moore argued that esse is not percipi. In particular, Moore claimed that "[w]e can and must conceive the existence of blue as something quite different from the existence of the sensation [of blue]" (Moore 1903, p. 445). That sounds like the claim that, for example, "a blue tie should exist at a time

\footnotetext{
${ }^{2}$ For arguments in support of the ambiguity thesis see Rosenthal (1999) and Brown (2006). Reid, who was an ambiguity theorist for 'smell' (Reid 1764/1997, p. 39), drew the line at color terms (Reid 1764/1979, pp. 101-102); see also section 4 below, and Clark (2000, pp. $1-2)$.
} 
when nothing is looking blue to anyone" (Moore 1942, p. 655), as Moore put it nearly forty years later in The Philosophy of $\underline{\text { G.E. }} \underline{\text { Moore. }}$.

However, in that volume, Moore goes on to tell us that:

this is not the question at issue ... In order to see what the issue is, It seems to me to be absolutely essential to see that such words as "blue" and "bitter" may be used in two very different senses. When we say of such things as a tie or a flag or an india rubber ball that they are blue, what we are saying about them may be something very different from what we are saying of an after-image, which we see with closed eyes, when we say that it is blue; and when we say of quinine or wormwood that they are bitter, what we are saying of them is certainly something very different from what we are saying of a taste which we are tasting or a taste "which is in our mouth," when we say that it is bitter. (Moore 1942, p. 655)

Forget for the moment about the wormwood, and concentrate on the alleged ambiguity in 'blue.' In one sense, it stands for a property of external objects like ties, rubber balls, and so on. In another sense, it stands for a property of an afterimage "or any other sense-datum" (Moore 1942, p. 658). In this second sense, 'blue' stands for what Moore calls "the sensible 
quality 'blue"' (Moore 1942, p. 658); to avoid confusion, let us adapt some terminology from Peacocke (1983), and call this quality instead 'the sensational quality blue.'3

We now have a third quality to contend with, at least nominally: the sensational quality blue, in addition to the sensible quality blue and the sensory quality blue (i.e., bluishness, as Levine would call it). Again borrowing some terminology from Peacocke, call the sensational quality blue, 'blue', ('blue-prime'). Blue' is a property of sense-data: objects of experiences, not experiences themselves. According to Moore, when a tie looks blue to one, one is (or can be) aware of something else, an immaterial (or at least not clearly material) thing that appears blue'. Even though the tie may not in fact be blue, the sensedatum is as it appears, and so is blue'.

Is there such a property as blue'? If 'blue' has 'two different senses' when we speak of a 'blue afterimage' and a 'blue tie,' then there is at least an initial reason for thinking so. But there appears to be no ambiguity: 'My afterimage and this tie are both exactly the same shade of blue' would strike us as false if 'blue' were ambiguous between 'the color blue' (not a property of afterimages) and 'blue'' (not a property of ties). On the contrary, this sentence seems unproblematically true. Of course, it might not in fact be true. Offhand, the sentence is true only if there are such things as afterimages, and arguably there are no afterimages, there only seem to be (see Smart 1959). But this would trace the falsity of the sentence to the metaphysics of afterimages, rather than to an ambiguity in 'blue.'

\footnotetext{
${ }^{3}$ Of course, traditionally sense-data were taken to be either colored items or else the colors themselves (see Moore 1953, pp. 28-40; Jackson 1977).
} 
Afterimages appear to be located on the focussed surface (Emmert's Law), and can be mistaken for colored patches. This would be mysterious if afterimages did not appear colored. Further, as explained in any textbook on color vision, there are theories of afterimages - these theories explain why, for instance, staring at a yellow surface will produce a blue afterimage. If afterimages are not blue (or do not appear blue), the widely accepted characterization of the data to be explained is wrong.

Moore's case for blue' is uncompelling. Let us briefly turn to his second example, of 'bitter.' Here the claim of ambiguity (or, better, polysemy) is considerably more plausible. Wormwood is bitter because it has a bitter taste, just as a skunk is malodorous because it produces a malodorous smell, and (to borrow Aristotle's example), an apple is healthy (in the secondary sense) because it is conducive to a healthy body (in the primary or focal sense). It is at least strained to say that wormwood and the taste it produces are both bitter.

Have we not found a sensational quality, bitter', which attaches to gustatory sense data? Not obviously: on the face of it, a bitter taste is some kind of bitter 'emanation' produced by wormwood, just as the sweet smell of lilacs is (on one understanding) a sweet effluvium produced by lilacs. Notice that Moore can't quite keep his scare quotes off the phrase, but there is no apparent reason why the taste should not be (spatially) in the mouth. 
A proponent of sensational qualities should look elsewhere for support, perhaps to Peacocke's much discussed arguments. But these are beyond the scope of this article. ${ }^{4}$

\section{Sensory qualities and natural signs}

According to a long tradition, external objects act on our perceptual apparatus to produce experiences with distinctive sensory qualities — or, alternatively, experiences of sense-data with distinctive sensational qualities. The epistemological problem of perception is then conceived as one of working out what the distal stimulus must be like, given that it produces these effects in us.

Thus Russell:

... if we take any common object of the sort that is supposed to be known by the senses, what the senses immediately tell us is not the truth about the object as it is apart from us, but only the truth about certain sense-data which, so far as we can

\footnotetext{
${ }^{4}$ For criticism, see Tye (2000, ch. 4). It should be noted that Peacocke's 'primed' notation is not quite as simple as our simplified variant of it. 'Blue',' as explained above, expresses a property of a sense-datum. However, Peacocke introduces primed expressions as expressing relations between experiences and regions of an "imagined interposed plane" perpendicular to the line of sight (Peacocke 1983, p. 20). However, later Peacocke speaks freely of "red" regions of the visual field" (Peacocke 1983, ch. 2; see also Peacocke 1984), where a 'region of the visual field' appears to be very much like a sense-datum.
} 
see, depend upon the relations between us and the object. Thus what we directly see and feel is merely 'appearance', which we believe to be a sign of some 'reality' behind. But if the reality is not what appears, have we any means of knowing whether there is any reality at all? And if so, have we any means of finding out what it is like? (Russell 1912/1980, p. 6)

This sort of view was set out with particular clarity by Thomas Reid. When a tomato is seen, Reid thinks, an "appearance" or "sensation" or what "Mr Locke calls ... an idea" (Reid 1764/1970, p. 100) of color is produced in the mind, and "[t]his sensation is followed by the perception of the object" (Reid 1764/1970, p. 214). The sensation, whose nature we can know perfectly, "suggests the conception and belief of some unknown quantity in the body, which occasions the idea; and it is to this quality, and not to the idea, that we give the name of colour" (Reid 1764/1970, p. 100). Here Reid takes himself to have an essentially linguistic dispute with Locke \& Co., whom Reid take to hold that "colour is not a quality of bodies, but only an idea in the mind" (Reid 1764/1970, p. 102). Reid thinks it is absurd to hold that the vulgar "give the name of colour to the sensation" (Reid 1764/1970, p. 101). Instead, color words denote the power in bodies to produce our color sensations, the “unknown cause" of a "known effect" (Reid 1764/1970, p. 101).

Borrowing Reidian terminology, let us call this picture of perception the natural sign theory. According to it, the only information solely about the color of a tomato that can be extracted from the experience of seeing it, is that the tomato has some property or other that 
causes experiences with the sensory quality of reddishness (the 'natural sign' of the sensible quality red).

\section{Natural signs and dispositionalist accounts of sensible qualities}

As the last paragraph hinted, there is an intimate relation between the natural sign theory and accounts of sensible qualities as dispositions to affect perceivers in certain ways. This connection is brought out in some striking passages from Evans' classic paper 'Things without the mind.'

After quoting Reid with approval (Evans 1980, p. 271), Evans claims that "[a]11 it can amount to for something to be red is that it be such that, if looked at in the normal conditions, it will appear red" (Evans 1980, p. 272). Some misguided philosophers deny this:

They have tried to make sense of the idea of a property of redness which is both an abiding property of the object, both perceived and unperceived, and yet 'exactly as we experience redness to be'. By concentrating upon one's experience of colour, one is supposed thereby to know what it is for an object to have this property: 'This', one is to say, referring neither to the experience nor to any primary property of the thing, 'this, just as it is, can exist in the absence of any observer'.

But the leap gets us nowhere, for it inevitably involves an attempt to make sense of an exemplification of a property of experience in the absence of 
experience. Wittgenstein once imagined a world in which there were places which affected everyone painfully, so that pains were located at places in the way we locate smells. Suppose this fantasy came true. Would it then make sense to give a non-dispositional account of what it is for there to be a pain at such and such a spot: to suppose a 'pain as we feel it' existing in the absence of any observer? What can the latter form of words mean save that something awful is going on there, and how can that be, when there is no one who is hurt? To modify a dictum of Wittgenstein, conceiving of a pain which no one feels on the model of a pain which one does feel is none too easy a thing to do. (Evans 1980, pp. 272-273; footnote omitted)

This passage is not easy to understand, but one interpretation (there may be others) leans heavily on Evans' remark about 'an exemplification of a property of experience.' and the analogy with Wittgenstein's example. So interpreted, the argument takes the natural sign theory as a premise, and runs as follows.

Start with pain, and assume that pains are 'painful' experiences. This view, unlike one that takes pains to be the intentional objects of certain experiences, and not the experiences themselves, makes pains "existing in the absence of any observer" decidedly suspect, just as Evans says. ${ }^{5}$ Further, assume the common view that painful experiences are

\footnotetext{
${ }^{5}$ The truth may be a confused amalgam of both views: sometimes we think of pains as intentional objects ('the pain is in my wrist'), and sometimes as experiences ('pain is a feeling') (see Harman 1990, p. 40).
} 
'mere' sensations: experiences with no representational content (and so no intentional objects). Now make the counterfactual supposition that Wittgenstein's fantasy is true: "The surface of the things around us (stones, plants, etc.) have patches and regions which produce pain in our skin when we touch them ... In this case we should speak of painpatches on the leaf of a particular plant just as at present we speak of red patches" (Wittgenstein 1953, §312). That is, suppose that certain surfaces are disposed to produce pain sensations (painful experiences) in us, and we use the word 'pain' to refer to a property of those surfaces that they possess even when no one is touching them. 'Pain,' as used in these counterfactual circumstances, can hardly refer to a property that our experiences represent certain surfaces as having, because ex hypothesi painful experiences have no representational content. Instead, the obvious candidate, given that 'pain' is used to refer to an abiding property of surfaces, is that it refers to the disposition to cause painful experiences in us.

The next step of the argument compares pain to color. When we look at a tomato, we have reddish sensations, experiences with a distinctive sensory quality, but with no representational content (no color content, anyway). Trying to make sense of "colour-aswe-see it" (Evans 1980, p. 273) when we don't see it amounts to making sense of reddishness, a 'property of experience,' 'exemplified in the absence of experience.' However, we use the word 'red' to refer, not to a property of experiences, but to an abiding property of objects. As with the pain-patches example, this word plausibly refers to a disposition to cause reddish sensations in us (a disposition to 'appear red,' as Evans 
unfortunately puts it). Thus the familiar 'secondary quality' theory of colors as dispositions or powers is established.

Once the natural sign theory is in place, the secondary quality theory is not far behind. However, the natural sign theory is mistaken.

One difficulty is the assumption of special epistemic access to the 'effect,' without which the natural sign theory would not get off the ground. And that, although it might be true, is unobvious and needs arguing for. (Here of course the spatial metaphor is pernicious - encouraging us to think that sensations are particularly accessible because they are 'in' the mind.)

But the decisive defect is this. The natural sign theory cannot accommodate the plain fact that objects look colored. Imagine that someone is looking at a tomato, and sees that it is red. If we apply the basic outline of the natural sign theory to the perception of the tomato's color, what is going on? First, a property of the tomato causes a certain effect in the perceiver: a reddish sensation. Second, she becomes aware that this sensation is reddish. Third, she forms the belief that the tomato has the power to cause reddish sensations (i.e. she believes that the tomato is red). End of story.

Of course, the tomato will look red to the perceiver. The natural sign theorist can say that this simply amounts to the fact that the perceiver believes that the tomato is red and has a reddish sensation. But now imagine that our perceiver does not in fact believe that the tomato is red - she suspects, say, that the lighting conditions are abnormal. The tomato will still look red to her. And this cannot be accommodated by the natural sign theory. According to it, the perceiver in this situation is having a reddish sensation, is aware that 
her sensation is reddish, and does not believe that the tomato is red. It is not very plausible that the tomato's looking or appearing red can be reconstructed from such meagre materials. Adding that the perceiver has some sort of tendency or disposition to believe that the tomato is red does not help much. If appearances are analysed partly in terms of dispositions to believe then there are no causal explanations of the latter in terms of the former. But, intuitively, there are such explanations: a perceiver might be disposed to believe that the tomato is red because it looks red. ${ }^{6}$

The inadequacy of the dispositional suggestion can be shown more convincingly by returning to Wittgenstein's pain patches. Notice that we sometimes do use 'painful' rather like the way 'pain' is used in Wittgenstein's imagined situation, as when we speak of painful nettles (or painful parts/areas of nettles). Suppose that someone is in pain, is touching a nettle, and does not believe that the nettle is painful (she takes her pain to be caused by a bee sting, and is generally ignorant about nettles). Further suppose, as may well be the case, that she has some suppressed inclination to believe that the nettle is painfulshe would have believed this had she not believed that she had been stung by a bee. Despite having such a disposition to believe, the nettle will not appear painful to her, as a tomato appears red: pain is felt in the skin, but never on a nettle.

There are other routes to the secondary quality theory, but they are considerably less direct. Contemporary proponents of one or another sophisticated variant of the secondary

\footnotetext{
${ }^{6}$ Since Evans basically makes this point elsewhere (Evans 1982, pp. 123-124), the interpretation of his argument in the text should be treated with some caution.
} 
quality theory reject the natural sign theory, at least in its full Reidian dress, but the assumption that there are sensory (or sensational) qualities is often crucial to their arguments (see, for instance, Peacocke 1983, ch. 2, 1984; McLaughlin 2003).

\section{Summary}

Historically, there has been a persistent tendency to identify sensible qualities with sensory qualities or sensational qualities - to take the striking quality of a tomato to be a quality of one's experience, or a quality of a sense-datum. Once the three kinds of qualities are separated, it is not so clear that there are any sensory or sensational qualities. And if there aren't, then a lot of the motivation for secondary quality theories of sensible qualities drains away. More threatens to be thrown out with the bathwater, since the 'hard problem' of consciousness arguably presupposes that there are sensory qualities. ${ }^{7}$

The issue is one of the major fault lines in contemporary philosophy of mind. Introspection is an unlikely way of making progress. A more promising method is to proceed on the assumption that sensory and sensational qualities are a myth, and see how quickly — or whether — one runs into sand.

\section{References}

\footnotetext{
${ }^{7}$ For the hard problem, see Chalmers (1996). For an argument that the hard problem vanishes if there are no sensory qualities, see Byrne (2006).
} 
Bennett, J., 1988. Events and Their Names. Indianapolis: Hackett.

Block, N., 1990. Inverted earth. Philosophical Perspectives, 4, 53-79.

Boring, E.G., 1933. The Physical Dimensions of Consciousness. New York: Century.

Brown, D.H., 2006. On the dual referent approach to colour theory. Philosophical

Quarterly, 56, 96-113.

Byrne, A., 2006. Color and the mind-body problem. Dialectica, 60, 223-244.

Chalmers, D., 1996. The Conscious Mind. In Search of a Fundamental Theory. Oxford: Oxford University Press.

Clark, A., 1993. Sensory Qualities. Oxford: Oxford University Press.

Clark, A., 2000. A Theory of Sentience. Oxford: Oxford University Press.

Evans, G., 1980. Things without the mind—A commentary upon chapter two of Strawson's Individuals. In: Z. van Straaten, ed. Philosophical Subjects, 76-117. Oxford: Oxford

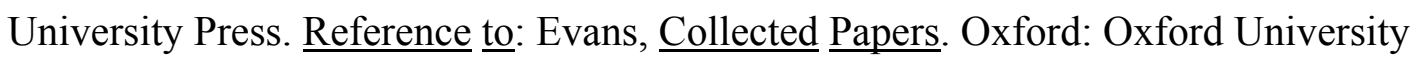
Press 1985, 249-290.

Evans, G., 1982. The Varieties of Reference. Oxford: Clarendon Press.

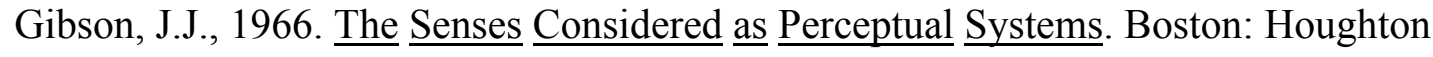
Mifflin.

Harman, G., 1990. The intrinsic quality of experience. Philosophical Perspectives, 4, 31 52.

Hayek, F.A., 1952. The Sensory Order: An Inquiry into the Foundations of Theoretical Psychology. Chicago: University of Chicago Press.

Hinton, J.M., 1973. Experience. Oxford: Oxford University Press. 


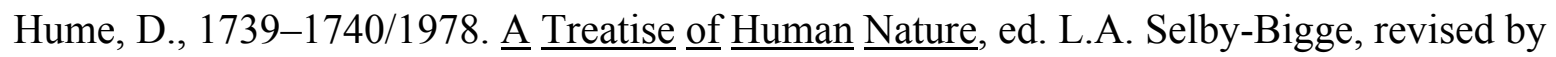
P.H. Nidditch. Oxford: Clarendon Press.

Jackson, F., 1977. Perception. Cambridge: Cambridge University Press.

Levine, J., 2001. Purple Haze: The Puzzle of Consciousness. Oxford: Oxford University Press.

Lycan, W., 1996. Consciousness and Experience. Cambridge, MA: MIT Press.

McLaughlin, B., 2003. The place of color in nature. In: R. Mausfeld and D. Heyer, eds. Colour Perception: Mind and the Physical World. Oxford: Oxford University Press, $475-502$.

Moore, G.E., 1903. The refutation of idealism. Mind, 12, 433-453.

Moore, G.E., 1942. A reply to my critics. In: P. Schillp, ed. The Philosophy of G.E. Moore. Chicago: Northwestern University Press, 535-677.

Moore, G.E., 1953. Some Main Problems of Philosophy. Allen \& Unwin: London.

Peacocke, C., 1983. Sense and Content. Oxford: Oxford University Press.

Peacocke, C., 1984. Colour concepts and colour experience. Synthese, 58, 365-382.

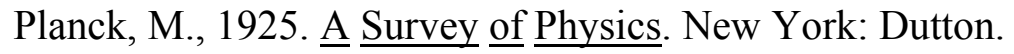

Reid, T., 1764/1970. An Inquiry into the Human Mind. Chicago: University of Chicago Press.

Rosenthal, D., 1999. The colors and shapes of visual experiences. In: D. Fisette, ed. Consciousness and Intentionality: Models and Modalities of Attribution. Dordrecht: Kluwer, 95-118.

Russell, B., 1912/1980. The Problems of Philosophy. Oxford: Oxford University Press. 
Smart, J.J.C., 1959. Sensations and brain processes. Philosophical Review, 68, 141-156.

Stuart, M., 2003. Locke's colors. Philosophical Review, 112, 57-96.

Tye, M., 2000. Consciousness, Color and Content. Cambridge, MA: MIT Press.

Wittgenstein, L., 1953. Philosophical Investigations. Oxford: Blackwell. 